\title{
Correlations between algal abundance, environmental variables and sponge distribution patterns on southern hemisphere temperate rocky reefs
}

\author{
César A. Cárdenas*, Simon K. Davy, James J. Bell \\ School of Biological Sciences, Victoria University of Wellington, PO Box 600, Wellington 6140, New Zealand
}

\begin{abstract}
Sponges are important components of temperate rocky reefs whose abundance and diversity are influenced by a range of biological and physical factors. In high light environments, sponges are generally less abundant and are often restricted to shaded microhabitats. However, this generalisation stems primarily from research conducted in the northern hemisphere, with comparatively little information from the southern hemisphere. The aim of the present study was to examine correlations between sponge abundance and assemblage composition and between algal abundance and environmental variables. We measured the distribution patterns of sponges relative to macroalgal abundance, physical factors (including depth, surface inclination, turbidity, rugosity and temperature) and the abundance of other phyletic groups at multiple sites in New Zealand. A negative correlation was found between sponge abundance and algal abundance, with surface inclination strongly correlating with the distribution patterns of both groups. Our results support the generalisation from previous studies in the northern hemisphere that sponge and algal abundance are negatively correlated.
\end{abstract}

KEY WORDS: Sponge - Macroalgae - Distribution patterns - Competition · Shallow water · Rocky reefs Resale or republication not permitted without written consent of the publisher

\section{INTRODUCTION}

Sponges are abundant components of rocky benthic communities in temperate (Ayling 1983, Bell \& Barnes 2000a), tropical (Diaz et al. 1990, Diaz \& Rützler 2001, Bell \& Smith 2004, de Voogd et al. 2009) and polar regions (Dayton et al. 1974, Barthel et al. 1991, Sarà et al. 1992, Teixidó 2003) whose abundance patterns are strongly influenced by a range of biological and physical factors. For example, the distribution and abundance patterns of sponges are strongly influenced by depth (Bell \& Barnes 2000d), water flow (Bell \& Barnes 2003), sedimentation (Carballo 2006), predation (Ayling 1981), salinity (Roberts et al. 2006), nutrient concentrations (Wilkinson \& Evans 1989), substrate type and angle (Bell \& Barnes 2000b), and turbidity (Zea 1994). In addition, a num- ber of these earlier studies suggest that these factors can indirectly influence sponges through their effects on other organisms; for example, light influences the abundance of algae, a potential spatial competitor of sponges. Separating the relative importance of these different factors remains challenging, and far less is known about how biological factors influence sponges compared to physical factors, particularly in the southern hemisphere.

Although sponges are dominant in many habitats, they are often restricted to the undersides of boulders or shaded surfaces in high light environments where macroalgae are abundant (Baynes 1999, Irving \& Connell 2002, Konar \& Iken 2005). Several authors have tried to clarify the spatial relationships between sponges and algae and have examined correlations between these 2 groups. For example, Bell \& Barnes 
$(2000 a, b)$ proposed that the higher diversity of sponges on vertical surfaces, compared to horizontal surfaces, was a result of reduced light intensity, resulting in reduced algal abundance. Furthermore, these authors also found strong correlations between depth and sponge abundance; where algal abundance declined, sponge abundance increased. Bell (2002, 2007) suggested that such negative correlations between sponges and algae might be explained by sponges only being able to persist in areas that are unsuitable or less suitable for algae or by sponges preferring habitats that are less favourable for algae (i.e. low light). Konar \& Iken (2005) proposed that the dominance of algae over sponges on the tops of boulders was the result of micro-habitat differences among surface orientations, including differences in sediment load and light intensity, preventing sponges from occurring on horizontal surfaces (Wilkinson \& Vacelet 1979, Maldonado et al. 2008). More recently, Preciado \& Maldonado (2005) found that substratum inclination strongly correlated with sponge and algal distribution patterns, suggesting that substratum inclination was the main factor structuring sponge assemblages in the shallow waters of the Mediterranean. These authors found that sponges were mostly restricted to overhangs, where factors considered to be detrimental to sponges (e.g. high light and high sedimentation) are reduced (Wilkinson \& Vacelet 1979, Jokiel 1980, Ginn et al. 2000, Roberts et al. 2006). However, in contrast to these results from northern hemisphere studies, no correlation was found between sponge and macroalgae abundance in rocky reefs on the south-east coast of Australia (Knott et al. 2004).

While there has been comparatively less study of the correlations between sponge and algal abundance in the southern hemisphere, the information that is available for correlations between sponges and algae seems to contrast with that from the better studied northern hemisphere. Therefore, the aims of our study were to: (1) re-examine the correlations between sponge abundance and distribution patterns with algal abundance and other environmental variables at study sites in the southern hemisphere; and (2) consider the specific influence of depth and surface inclination on sponge abundance and assemblage structure because these 2 variables are also likely to influence algal abundance.

\section{MATERIALS AND METHODS}

\section{Study sites}

Subtidal surveys were carried out at 7 sites along the south coast of Wellington and at Kapiti Island on the coast of North Island in New Zealand. Study sites on the coast of Wellington included Breaker Bay, Barrett Reef, Palmer Head, Princess Bay and The Sirens Rocks; the 2 sites studied at Kapiti Island were Trig Point and Kaiwharawhara Point (Fig. 1).

The Wellington coast sites were chosen to represent a wide range of different environmental and biological characteristics, enabling us to determine which factor or combination of factors best explained sponge spatial distribution patterns. The sites were characterised by the presence of relatively continuous bedrock and steep walls. The Wellington coast is an energetic environment that is subjected to regular southerly swells that move onto the Wellington shelf $>80 \%$ of the time (Carter \& Lewis 1995). The algal assemblage is mainly dominated by Ecklonia radiata and a mixture of Carpophyllum spp., Lessonia variegata and Landsburgia quercifolia (Shears \& Babcock 2007). The understory is dominated by crustose coralline algae (CCA), and the overall abundance of
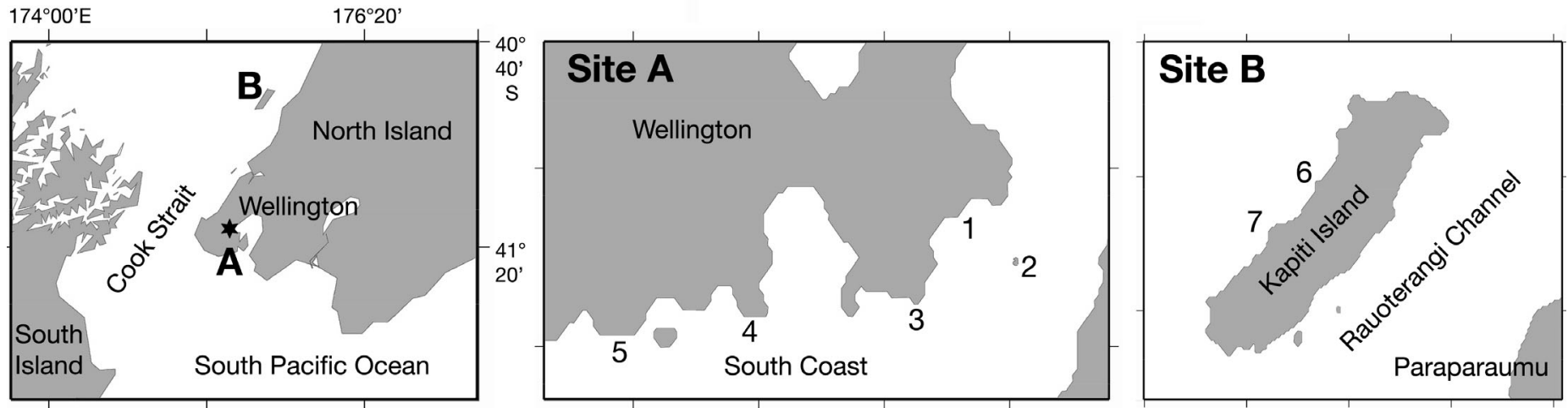

Fig. 1. Location of study sites at Site A: south coast of Wellington, and Site B: Kapiti Island, New Zealand. 1: Breaker Bay; 2: Barrett Reef; 3: Palmer Head; 4: Princess Bay; 5: The Sirens Rocks; 6: Trig Point; 7: Kaiwharawhara Point 
sessile invertebrates has been reported to be low (Shears \& Babcock 2007). Nevertheless, recently Berman \& Bell (2010) reported a diverse sponge assemblage in this region, where sponge cover exceeds $50 \%$ of the substratum at some sites.

Kapiti Island is located off the west coast of the North Island of New Zealand, $50 \mathrm{~km}$ north of Wellington. Our study sites were located on the west coast of the island and are exposed to relatively strong tidal currents and regular strong north-westerly or south-westerly winds (Chiswell \& Stevens 2010). The area is characterised by an extensive boulder reef and larger blocks of bedrock (Baxter 1987). The habitats are dominated by a mixed Ecklonia radiata/Carpophyllum spp. forest in the shallow zone and forest consisting of only $E$. radiata in the deeper zone (below $10 \mathrm{~m}$ ). The understory contains a rich community of turf algae, bryozoans, sponges and ascidians (Battershill et al. 1993, Shears \& Babcock 2007).

\section{Sampling}

Surveys were conducted by SCUBA at 2 depths ( 5 and $15 \mathrm{~m}$ ) at each site. Breaker Bay and The Sirens Rocks were only surveyed at $5 \mathrm{~m}$ because of the absence of rocky reefs below $10 \mathrm{~m}$. At each depth, a series of five $0.25 \mathrm{~m}^{2}$ quadrats were haphazardly placed on the benthos and photographed with a digital camera (all sites had similar levels of available vertical, horizontal, inclined and overhanging surfaces). Quadrats were photographed in 2 layers: canopy (first layer) and understory (second layer). Quadrats were subdivided into 4 smaller sections to improve the level of resolution for the different groups of organisms. Each quarter was photographed, first with the canopy in place and then after the canopy was moved aside, and the picture quality enabled even the smallest sponge patches $(<1 \mathrm{~mm})$ to be identified. Depth was measured using a dive computer (UWATEC Smart Pro). Additional information was collected for each quadrat, including inclination, rugosity and orientation with respect to the dominant swells (as a surrogate of exposure). The inclination angle was categorised into horizontal $\left(\sim 0^{\circ}\right)$, inclined $\left(\sim 45^{\circ}\right)$, vertical $\left(\sim 90^{\circ}\right)$ and overhanging surfaces $\left(\sim 125^{\circ}\right)$. The rugosity was estimated in situ by measuring the bottom contour distance between the corners of the quadrat. Subsequently, a rugosity index was estimated based on the ratio of the measured bottom contour distance and the straight-line distance between the extremes of the quadrat $(70 \mathrm{~cm})$. The orientation of each quadrat (with respect to dominant swells) was included as an ordinal categorical variable: sheltered (for quadrats facing $\mathrm{W}-\mathrm{NE}$ ) = 0 ; semi-exposed $($ ENE-E) $=1$; exposed $(\mathrm{SE}-\mathrm{SW})=2$. At each site, physical variables of the water column were recorded at both depths with a CTD (RBR XR-420). Variables included turbidity, temperature, salinity, conductivity and chlorophyll (Table 1).

Each photo-quadrat was analysed with CPCe v3.5 (Coral Point Count with Excel extensions; Kohler \& Gill 2006) by superimposing a grid of points onto each picture. The percentage cover of the first layer (canopy) was measured, and then the cover of the second layer containing the sponges, macroalgae (erect non-calcareous algae), coralline algae (erect and encrusting), other encrusting organisms, bare rock and settled sediment was estimated in each quadrat. Settled sediment was estimated as the area of rock surface covered in sediment in each picture. Organisms were placed in the following categories: Porifera, Hydrozoa, Anthozoa, Polychaeta, Bryozoa, Ascidiacea, Rhodophyta (erect non-calcareous algae), Chlorophyta, Phaeophyta and CCA. Abiotic categories included bare rock and sediment. Percentage cover estimates were made for each category/taxon. All taxa in the photo-quadrats were identified to the lowest taxonomic level possible. A grid of 100 points was superimposed over each photo-quadrat to estimate canopy cover, and 100 points were used for each section of the quadrat (4 for each quadrat) to estimate the cover of the understory (400 points in total).

\section{Data analysis}

The number of sponge taxa was estimated for each quadrat, and mean values were obtained for each site. To estimate the mean number of sponge species for the different surface inclinations, the number of species per quadrat, for each inclination, was combined to obtain a mean value for each surface inclination across all sites for each depth. Differences in the mean number of species between sites ( 7 levels, random), depth (2 levels, fixed) and surface inclinations (4 levels, fixed) were tested using a permutational ANOVA (PERMANOVA) (Anderson 2001).

The percentage cover of organisms, bare rock and settled sediment were averaged across quadrats for comparisons among sites $(n=8$ per site as there were 2 depths, except for those sites where only $5 \mathrm{~m}$ was sampled; see 'Sampling'). The same routine was undertaken for comparisons among depths ( $\mathrm{n}=$ 5 per depth) and surface inclinations $\left(\mathrm{n}_{\text {horizontal }}=19\right.$; 
Table 1. Mean values $( \pm 1 \mathrm{SE})$ for the physical parameters of the water column measured at each study site on the south coast of Wellington and at Kapiti Island

\begin{tabular}{|lrcrrrr|}
\hline Site & $\begin{array}{c}\text { Depth } \\
(\mathrm{m})\end{array}$ & $\begin{array}{c}\text { Temperature } \\
\left({ }^{\circ} \mathrm{C}\right)\end{array}$ & $\begin{array}{c}\text { Salinity } \\
(\mathrm{PSU})\end{array}$ & $\begin{array}{c}\text { Turbidity } \\
(\mathrm{NTU})\end{array}$ & $\begin{array}{c}\text { Chlorophyll } \\
\left.(\mu \mathrm{g} \mathrm{l})^{-1}\right)\end{array}$ & $\begin{array}{c}\text { Conductivity } \\
\left(\mathrm{mS} \mathrm{cm}^{-1}\right)\end{array}$ \\
\hline Breaker Bay & 5 & $13.99 \pm 0.04$ & $34.76 \pm 0.02$ & $4.65 \pm 0.75$ & $0.39 \pm 0.06$ & $41.68 \pm 0.01$ \\
Barrett Reef & 5 & $15.25 \pm 0.01$ & $35.17 \pm 0.02$ & $3.00 \pm 0.78$ & $0.65 \pm 0.05$ & $43.34 \pm 0.03$ \\
& 15 & $15.24 \pm 0.01$ & $35.10 \pm 0.07$ & $5.33 \pm 0.65$ & $1.00 \pm 0.08$ & $43.17 \pm 0.08$ \\
Palmer Head & 5 & $16.66 \pm 0.01$ & $34.91 \pm 0.01$ & $1.35 \pm 0.24$ & $0.45 \pm 0.07$ & $44.47 \pm 0.01$ \\
& 15 & $16.53 \pm 0.01$ & $34.90 \pm 0.01$ & $3.35 \pm 0.41$ & $0.40 \pm 0.06$ & $44.71 \pm 0.04$ \\
Princess Bay & 5 & $15.22 \pm 0.01$ & $35.18 \pm 0.01$ & $0.73 \pm 0.01$ & $0.69 \pm 0.01$ & $43.34 \pm 0.01$ \\
& 10 & $14.99 \pm 0.04$ & $35.16 \pm 0.02$ & $8.67 \pm 1.24$ & $0.47 \pm 0.01$ & $43.11 \pm 0.04$ \\
The Sirens Rocks & 5 & $14.56 \pm 0.01$ & $34.73 \pm 0.01$ & $13.03 \pm 0.01$ & $0.39 \pm 0.01$ & $42.19 \pm 0.01$ \\
Kaiwharawhara Point & 5 & $18.14 \pm 0.02$ & $35.10 \pm 0.01$ & $1.88 \pm 0.35$ & $2.2 \pm 0.51$ & $46.17 \pm 0.02$ \\
& 15 & $17.75 \pm 0.01$ & $35.11 \pm 0.02$ & $2.53 \pm 0.42$ & $0.71 \pm 0.01$ & $45.78 \pm 0.01$ \\
Trig Point & 5 & $15.80 \pm 0.01$ & $35.11 \pm 0.01$ & $0.35 \pm 0.01$ & $0.55 \pm 0.01$ & $43.83 \pm 0.01$ \\
& 15 & $15.72 \pm 0.01$ & $35.01 \pm 0.01$ & $11.7 \pm 0.97$ & $0.59 \pm 0.01$ & $43.64 \pm 0.01$ \\
\hline
\end{tabular}

$\mathrm{n}_{\text {inclined }}=12 ; \mathrm{n}_{\text {vertical }}=22 ; \mathrm{n}_{\text {overhanging }}=12$ as data was combined across all sites). Percentage cover data were double square root transformed to downweigh the influence of extreme values (i.e. rare and very abundant species); this enabled us to test for differences in cover between sites, depths and inclinations. PERMANOVA (Anderson 2001) based on a Bray-Curtis similarity matrix (Bray \& Curtis 1957) was performed to test for differences in assemblage structure among these a priori factors. This test was used because the data did not meet the assumptions of normality and equal variance, even after transformation. Factors considered in the analysis were site (5 levels, random), depth (2 levels, fixed) and inclination (4 levels, fixed). Statistical differences were tested using 9999 permutations under a reduced model. PERMANOVA tests were applied to the full dataset to examine multivariate patterns at the category level. PERMANOVA tests were also used to examine differences in the percentage cover of the dominant benthic groups (treated as univariate measures) between sites, depths and inclinations. All procedures were conducted within PRIMER v6 (Clarke \& Gorley 2006, Anderson et al. 2007).

Scatterplots were used to visualise the relationships among sponge, CCA and algal abundance (separated into canopy and understory), and the curve fitter option in the software SlideWrite v5 (Advanced Graphics Software 1999) was used to fit linear and non-linear functions to plots to determine the best fit to the data. The curve fitter function fits 40 different linear functions and 60 different non-linear functions (10 exponential, 25 power and 25 polynomial) to each scatter plot. For the non-linear functions, the method employs the Levenberg-Marquardt algorithm in an unconstrained optimisation approach to estimate the coefficients of the equation (Advanced Graphics Software 1999).

To analyse the relationship between the percentage cover of benthic organisms and the different environmental factors and biological groups, an ordination method was applied using CANOCO v4.5 (ter Braak \& Smilauer 2002). Two ordination analyses were performed to test the relationship between organisms and environmental variables. The first analysis was for the whole data set to analyse the overall community at the category level, and the second analysis included sponges at species level. To downweigh the influence of rare species, the cover data were double square root transformed. The environmental and biological variables used in the analysis were inclination, depth, orientation, turbidity, rugosity, water temperature, salinity, conductivity, percentage cover of CCA, percentage cover of canopy algae (first layer), algal understory (erect algae-second layer) and percentage of settled sediment on the substrate. Detrended canonical correspondence analysis (DCCA) was conducted to calculate the gradient length. DCCA yielded a short gradient (>3) for both cases, and a redundancy analysis (RDA) was then applied (ter Braak \& Smilauer 2002, Leps \& Smilauer 2003). A Monte-Carlo test was used to test the statistical significance of the first axis and all canonical axes combined using 9999 permutations under the reduced model. Automatic selections of variables were used to identify the 5 most significant variables. The variance inflation factors (VIF) were used to assess linear dependencies among the variables. Variables with a VIF $<5$ were maintained in the analysis. RDA results were represented graphically in a scaling bi-plot (2dimensional ordination), focusing on inter-species 
distances. Categories/species were graphically represented as circles and variables as vectors. The vectors show the direction in which the value of the variable of interest increases, and the length shows its relative importance in explaining species' distributions. The category/species symbols can be projected onto the vectors (variables) to approximate the optimal individual category/species with respect to values of the variable.

\section{RESULTS}

\section{Sponge species richness}

The mean $( \pm \mathrm{SE})$ number of taxa per quadrat varied between sites (PERMANOVA, $\mathrm{p}<0.05$; Table 2); the lowest value was observed at Princess Bay (3.6 \pm $1.00)$ and the highest at Breaker Bay $(13.5 \pm 1.32)$, with the latter site significantly different from the majority of the other sites (Fig. 2a). Although the area sampled by each quadrat was small $\left(0.25 \mathrm{~m}^{2}\right)$, the high values obtained for species richness suggest that quadrat size did not significantly bias our sampling. No differences were found in the number of taxa per quadrat between depths (PERMANOVA, $\mathrm{p}>0.05)$. The number of taxa per quadrat ranged between $6.9( \pm 0.92)$ at $15 \mathrm{~m}$ and $7.9( \pm 0.92)$ at $5 \mathrm{~m}$. The mean number of taxa per quadrat varied significantly between surface inclinations (PERMANOVA, $\mathrm{p}<0.05$; Table 2), ranging from $2.92( \pm 0.57)$ on horizontal surfaces to $13.3( \pm 0.92)$ on overhanging surfaces (Fig. 2b). In most cases, the species richness differed between inclination types (Fig. 2).

\section{Distribution patterns of benthic organisms}

The mean $( \pm \mathrm{SE})$ percentage cover of CCA differed among sites (PERMANOVA, $\mathrm{p}<0.05$ ) and was greatest at Palmer Head $(53.7 \pm 4.4 \%)$ and lowest at Trig Point $(21.4 \pm 4.5 \%)$. Red erect algae (Rhodophyta) was most abundant at Barrett Reef, with a mean percentage cover of $17 \%$, while Phaeophyta was most conspicuous at Kapiti Island sites, with $\sim 14 \%$ cover; differences among sites were significant (Table 3). Chlorophyta abundance was generally low and was only abundant at Princess Bay and The Sirens Rocks (Fig. 3a). Sponges were the most conspicuous sessile invertebrates; their mean percentage cover was significantly different among sites (Table 3), being highest at Trig Point $(20.6 \pm 3.0 \%)$ and lowest at Princess Bay $(3.9 \pm 1.4 \%)$. Sponge cover was also high at
Table 2. Permutational analysis of variance (PERMANOVA) based on a Bray-Curtis similarity matrix, testing the effect of site ( 7 levels, random), depth (2 levels, fixed) and inclination (4 levels, fixed) on species/taxa richness. Statistical differences were tested using 9999 permutations under a reduced model. ${ }^{*} \mathrm{p}<0.05$

\begin{tabular}{|lcccl|}
\hline Factor & df & MS & $F$ & $\mathrm{p}$ \\
\hline Site & 6 & 2121.5 & 2.5893 & $0.018^{*}$ \\
Depth & 1 & 149.07 & 0.1429 & 0.8708 \\
Inclination & 3 & 2134.9 & 3.1509 & $0.0197^{*}$ \\
Site $\times$ Depth & 4 & 1190.9 & 1.4535 & 0.235 \\
Site $\times$ Inclination & 12 & 7508.3 & 0.7636 & 0.672 \\
Depth $\times$ Inclination & 3 & 2370 & 0.7568 & 0.6347 \\
Site $\times$ Depth $\times$ Incl. & 3 & 3214.2 & 1.3076 & 0.2823 \\
Residual & 32 & 819.34 & & \\
Total & 64 & & & \\
\hline
\end{tabular}

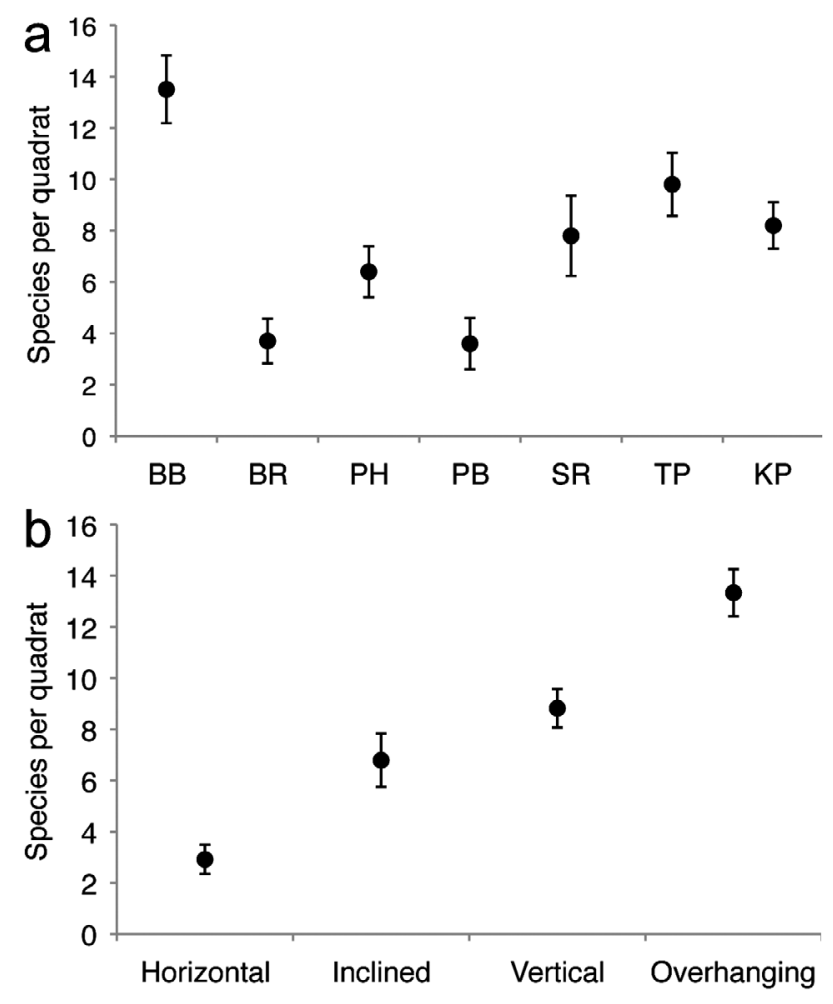

Fig. 2. (a) Mean $( \pm \mathrm{SE})$ sponge species richness recorded at different sites. (b) Mean $( \pm \mathrm{SE})$ species richness recorded for surface inclinations. BB: Breaker Bay; BR: Barrett Reef; PH: Palmer Head; PB: Princess Bay; SR: The Sirens Rocks; TP: Trig Point; KP: Kaiwharawhara Point. Percentage cover values of each sample were pooled for each site and surface inclination. Pairwise comparisons for sites showed significant differences between $\mathrm{BR}$ and $\mathrm{BB}, \mathrm{KP}$ and $\mathrm{BB}, \mathrm{PB}$ and $\mathrm{BB}, \mathrm{PH}$ and $\mathrm{PB}, \mathrm{SR}$ and $\mathrm{BB}, \mathrm{TP}$ and $\mathrm{BR}, \mathrm{PB}$ and $\mathrm{KP}$ and $\mathrm{TP}$ and $\mathrm{PB}$ $(p<0.05)$. Significant differences were found in all comparisons between inclinations, except for vertical vs. inclined $(\mathrm{p}>0.05)$ 
The Sirens Rocks and Breaker Bay in Wellington (Fig. 3a), where both sites were characterised by the presence of steep-walled channels.

Differences in community structure were found among sites (PERMANOVA, $\mathrm{p}<0.001$; Table 4 ) and types of surface inclinations; there was also a significant interaction between site and depth (PERMANOVA, $p<0.05$; Table 4 ), meaning that the effect of depth varied among sites. There was a significant effect of depth at Barrett Reef, Princess Bay and Kaiwharawhara Point (PERMANOVA, $\mathrm{p}<0.05$ ) but not at Palmer Head and Trig Point $(p>0.05)$. The greatest differences in community structure were observed between Trig Point at Kapiti Island and most of the sites on the Wellington south coast, except Breaker Bay, which was more similar to the sites studied at Kapiti Island than the sites located in Wellington. Percentage cover of sponges, CCA and red erect algae varied between depths (PERMANOVA, p < 0.001), whereas no differences were found in the cover of Phaeophyta and Chlorophyta (PERMANOVA, $\mathrm{p}>0.05$; Table 3).

We also found significant differences in sponge percentage cover (mean $\pm \mathrm{SE}$ ) on different surface inclinations, ranging from $5.5 \pm 2.0 \%$ on horizontal surfaces to $38.8 \pm 5.8 \%$ on overhanging surfaces (PERMANOVA, $\mathrm{p}<0.001$; Table 3). In contrast, the cover of erect algae decreased with increasing inclination, having the lowest abundance on overhangs (PERMANOVA, $\mathrm{p}<0.001$; Fig. 3b). CCA had lowest abundance on inclined surfaces $(42.8 \pm 6.44 \%)$ and highest abundance on overhangs $(13.7 \pm 7.67 \%$; PERMANOVA, $\mathrm{p}<0.05)$. Canopy cover was greatest at Palmer Head, with $89 \pm 3.3 \%$ cover at $5 \mathrm{~m}$ and 39 $\pm 11.2 \%$ at $15 \mathrm{~m}$. Sites at Kapiti Island showed the same pattern of decreased canopy cover with depth. The most important canopy-forming species were Ecklonia radiata, Lessonia variegata and Carpophyllum maschalocarpum.

When sponge abundance was correlated with algal cover and canopy cover, an exponential relationship was observed in both cases (Fig. 4). However, the lat-
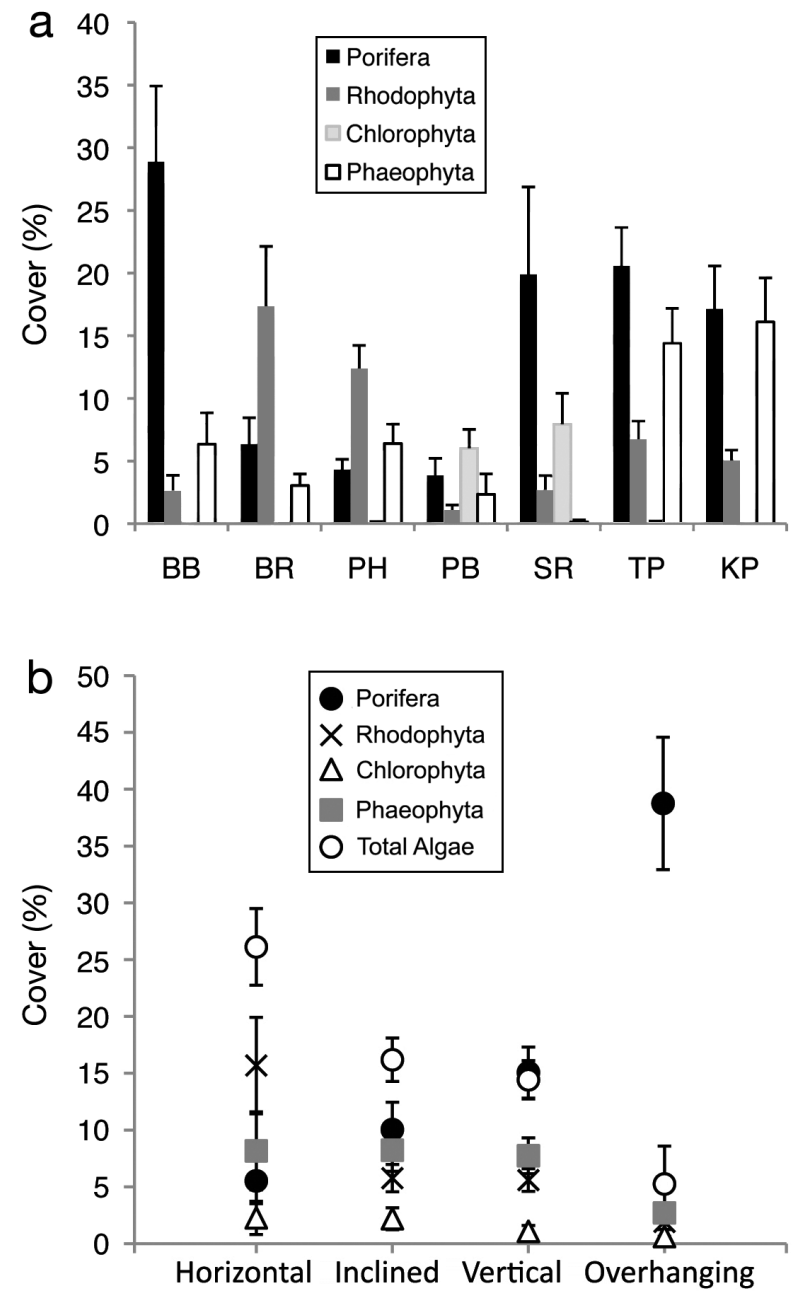

Fig. 3. (a) Mean ( $\pm \mathrm{SE}$ ) percent cover of sponges and macroalgae across sites studied on the south coast of Wellington and at Kapiti Island. See Fig. 2 for site labels. (b) Mean $( \pm \mathrm{SE})$ percent cover of sponges and macroalgae for different surface inclinations. Percentage cover values for each sample were pooled for each surface inclination

ter correlation was weak $\left(\mathrm{r}^{2}=0.387, \mathrm{p}<0.001\right)$. Nonetheless, when sponge cover was correlated against canopy cover (first layer), a significant negative correlation was found $\left(\mathrm{r}^{2}=0.546, \mathrm{p}<0.001\right)$. Linear relationships fitted to both data sets were much

Table 3. PERMANOVA to test for differences between sites, depths and inclinations in the percentage cover of dominant benthic groups. Statistical differences were tested using 9999 permutations of raw data. ${ }^{*} \mathrm{p}<0.05,{ }^{* *} \mathrm{p}<0.001$

\begin{tabular}{|c|c|c|c|c|c|c|}
\hline \multirow[t]{2}{*}{ Taxa } & \multicolumn{2}{|c|}{ Site } & \multicolumn{2}{|c|}{ Depth } & \multicolumn{2}{|c|}{ Inclination } \\
\hline & $F(\mathrm{df})$ & $\mathrm{p}$ & $F(\mathrm{df})$ & $\mathrm{p}$ & $F(\mathrm{df})$ & $\mathrm{p}$ \\
\hline Porifera & $4.9068(6,64)$ & $0.0001^{* *}$ & $4.733(1,64)$ & 0.057 & $5.3415(3,64)$ & $0.0002^{* *}$ \\
\hline Rhodophyta & $10.664(6,64)$ & $0.001^{* *}$ & $6.1242(1,64)$ & $0.014^{*}$ & $4.7227(3,64)$ & $0.002^{* *}$ \\
\hline Chlorophyta & $27.983(6,64)$ & $0.0001^{* *}$ & $0.2080(1,64)$ & 0.6693 & $0.5095(3,64)$ & 0.6936 \\
\hline Phaeophyta & $4.796(6,64)$ & $0.0001^{* *}$ & $1.9618(1,64)$ & 0.1398 & $1.5838(3,64)$ & 0.1665 \\
\hline $\mathrm{CCA}$ & $2.4961(6,64)$ & $0.0227^{*}$ & $7.2963(1,64)$ & $0.0045^{* *}$ & $6.9703(3,64)$ & $0.0004^{* *}$ \\
\hline
\end{tabular}


Table 4. PERMANOVA based on a Bray-Curtis similarity matrix, testing the effect of site (5 levels, random), depth (2 levels, fixed) and inclination (4 levels, fixed) on the overall community. Statistical differences were tested using 9999 permutations under a reduced model. ${ }^{*} \mathrm{p}<0.05,{ }^{* *} \mathrm{p}<0.001$

\begin{tabular}{|lcccl|}
\hline Factor & df & MS & $F$ & $\mathrm{p}$ \\
\hline Site & 4 & 3814.2 & 11.91 & $0.0001^{* *}$ \\
Depth & 1 & 5370.3 & 4.0401 & 0.0742 \\
Inclination & 3 & 806.55 & 3.326 & $0.0169^{*}$ \\
Site $\times$ Depth & 4 & 1001 & 3.1257 & $0.0011^{*}$ \\
Site $\times$ Inclination & 7 & 224.68 & 0.7016 & 0.803 \\
Depth $\times$ Inclination & 3 & 263.02 & 0.82844 & 0.5611 \\
Site $\times$ Depth $\times$ Incl. & 3 & 317.22 & 0.99055 & 0.49625 \\
Residual & 24 & 320.24 & & \\
Total & 49 & & & \\
\hline
\end{tabular}

weaker than those for the exponential relationships ( 0.1 and 0.3 , respectively). No relationship was found between percentage cover of sponges and CCA $\left(\mathrm{r}^{2}=\right.$ $0.1934, \mathrm{p}>0.05$; Fig. 4c). When sponge cover was plotted against canopy, algal and CCA abundance for each individual inclination type, no significant correlations were found in most cases, except for sponge coverage versus canopy cover and algal abundance on inclined surfaces $\left(\mathrm{r}^{2}=0.9286\right.$ and 0.9283, $\mathrm{p}<0.001$, respectively).

\section{Relationships between algal abundance, environmental variables and benthic assemblages}

The variation in community composition relative to the different environmental variables is shown in Fig. 5a. The first 2 axes accounted for $64.4 \%$ of the variation in the community structure. The MonteCarlo test results showed that the first and all canonical axes were significant $(p=0.001)$. The most important variables were inclination, percentage cover of CCA, canopy cover, percentage cover of settled sediment and algal abundance. The RDA showed that the community composition of encrusting invertebrates was positively correlated with surface inclination and not with the other variables. Sponges were positively correlated with surface inclination, especially with vertical and overhanging surfaces. The RDA generally confirmed the results of the correlation analysis in identifying a significant negative correlation between sponges and the algal canopy; however, it also showed a negative correlation between sponges and CCA, which was not observed using the correlation analysis.

Analysis of the sponge assemblages showed how different sponge taxa correlated with the different environmental and biological variables (Fig. 5b). According to the Monte-Carlo tests, the first and all canonical axes were significant $(p=0.001)$. The first 2 axes accounted for 19.0 and $22.8 \%$ of the variation in the species data, respectively, and both axes accounted for $84.5 \%$ of the variance of the speciesenvironment relationships. The first axis was determined mainly by canopy cover $(\mathrm{r}=-0.61)$, inclination $(\mathrm{r}=0.56)$ and CCA $(\mathrm{r}=-0.49)$, and the second axis was determined by algal abundance $(\mathrm{r}=-0.43)$. The RDA showed that most taxa were highly correlated with inclination. The majority of sponge taxa were negatively correlated with algal canopy cover (first layer), and algal understory and CCA, whereas a few species, such as Polymastia crocea and Haliclona sp.
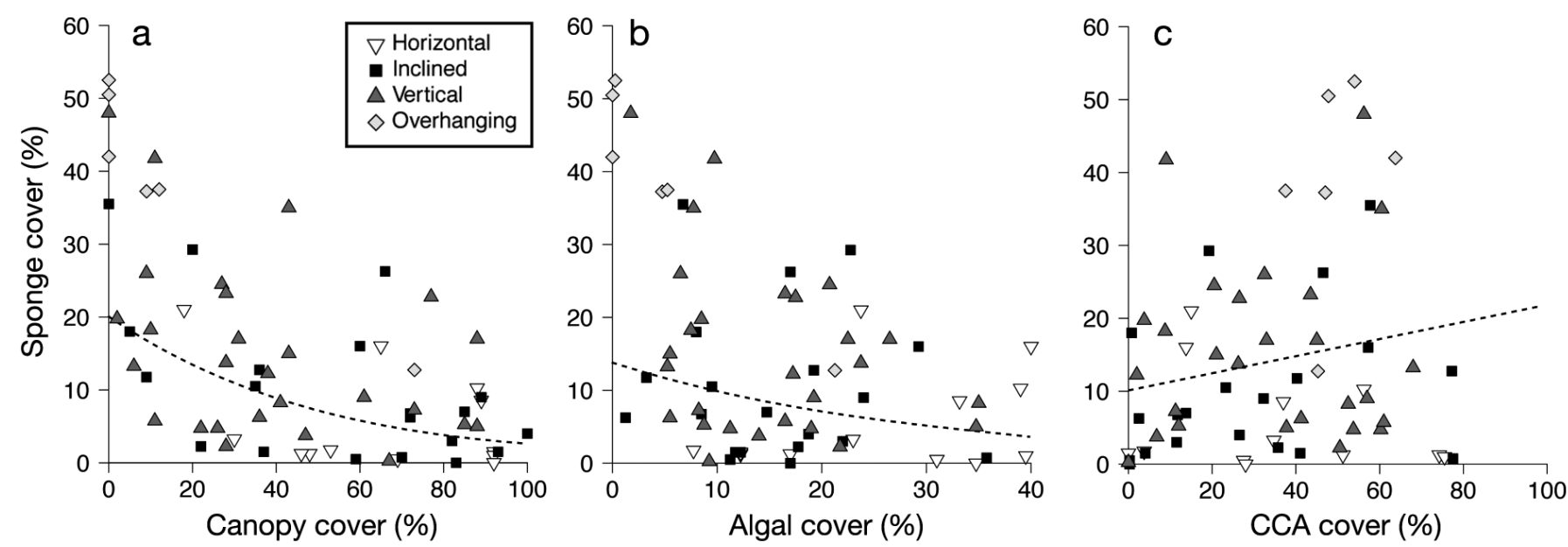

Fig. 4. (a) Relationship between sponge and canopy cover per quadrat $\left(y=35.2678 \times \exp ^{-0.0296 x}, r^{2}=0.546, p<0.001\right)$. (b) Relationship between sponge and macroalgae cover per quadrat $\left(y=35.3829 \times \exp ^{-0.0799 x}, r^{2}=0.387, p<0.001\right)$. (c) Relationship between sponge and crustose coralline algae (CCA) cover per quadrat $\left(y=\exp ^{0.0415 x}, \mathrm{r}^{2}=0.004, \mathrm{p}<0.001\right)$. Curves were fitted by the SlideWrite curve fitter (Advanced Graphics Software 1999). Scale for $x$-axis differs among panels 

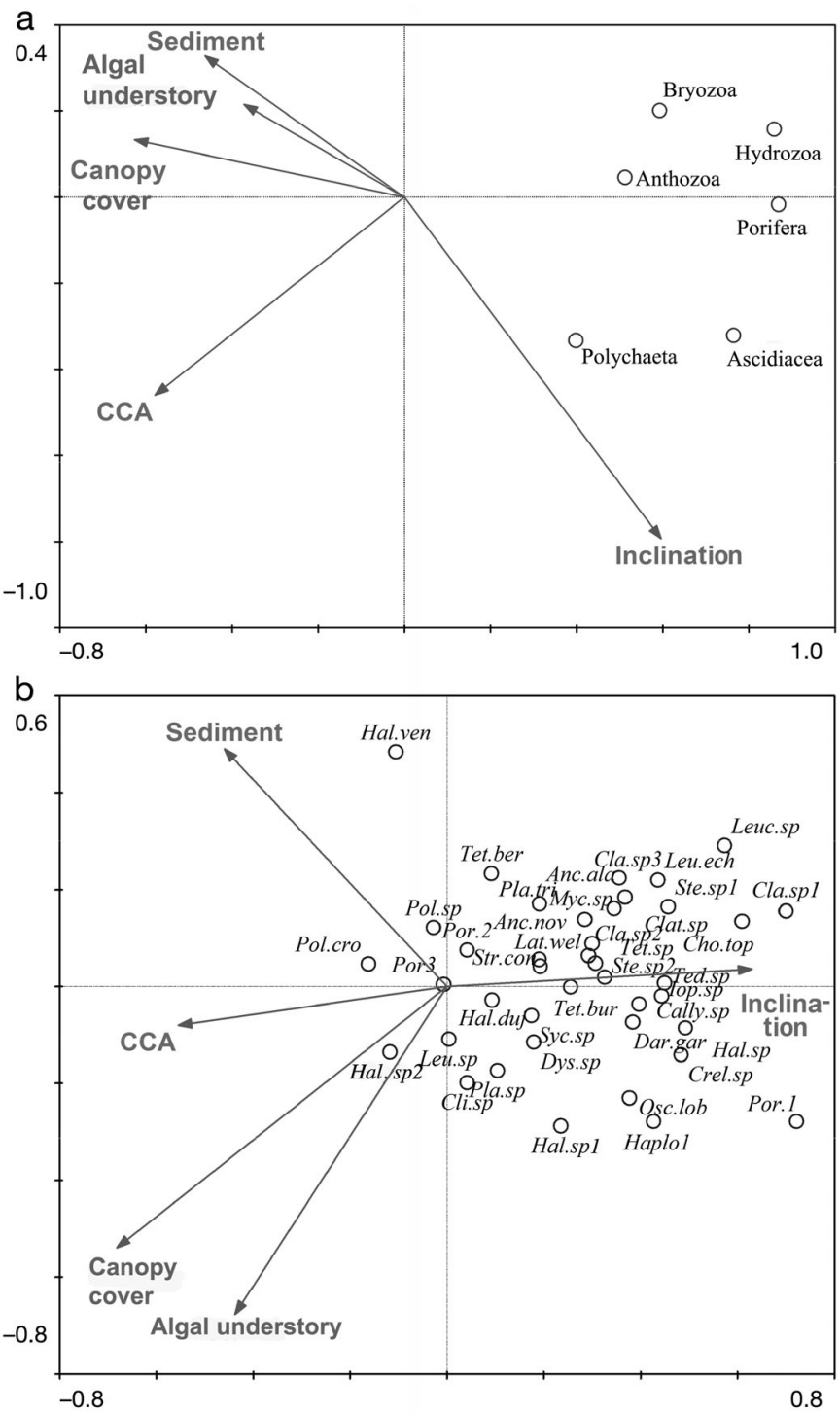

Fig. 5. Ordination plot of (a) the overall community and variables and (b) sponge assemblages and variables based on a redundancy analysis (RDA-biplot). Vectors represent the environmental variables, and species are represented as circles. Anc.ala: Ancorina alata; Anc.nov: Ancorina novaezelandiae; Cally.sp: Callyspongia sp.; Cho.top: Chondropsis topsenti; Clat.sp: Clathria sp.; Cla.sp1: Clathrina sp. 1; Cla.sp2: Clathrina sp. 2; Cla.sp3: Clathrina sp. 3; Cli.sp: Cliona sp.; Crel.sp: Crella sp.; Dar.gar: Darwinella sp.; Dys.sp: Dysidea sp.; Hal.sp 1: Haliclona sp. 1; Hal.sp 2: Haliclona sp. 2; Hal.ven: Haliclona venustina; Hal.duj: Halisarca dujardini; Hal.sp: Halisarca sp.; Iop.sp: Iophon sp.; Lat.wel: Latruncullia wellingtonensis Leuc.sp: Leucetta sp.; Leu.ech: Leucosolenia echinata; Leu.sp: Leucosolenia sp.; Myc.sp: Mycale sp.; Osc.lob: Oscarella lobularis; Pla.tri: Plakina trilopha; Pla.sp: Plakina sp.; Pol.cro: Polymastia crocea; Pol.sp: Polymastia sp. Por.1: Unidentified Porifera 1; Por.2: Unidentified Porifera 2; Por.3: Unidentified Porifera 3; Ste.sp1: Stelletta sp. 1; Ste.sp2: Stelletta sp. 2; Str.con: Strongylacidon conulosum; Syc.sp: Sycon sp.; Ted.sp: Tedania sp.; Tet.ber: Tethya bergquistae; Tet.bur: Tethya burtoni;

Tet.sp: Tethya sp.; Haplo1: Unidentified haplosclerid 1
2, were positively correlated with these variables. The settled sediment cover on the substratum negatively correlated with the abundance of the majority of the sponge species, with most being associated with low levels of settled sediment. Some species, such as Tedania sp., Oscarella lobularis and the calcareous sponges Clathrina spp. and Leucosolenia echinata, were more abundant on vertical and overhanging surfaces.

\section{DISCUSSION}

Supporting previous studies from the northern hemisphere, we found that sponge abundance and richness were strongly correlated with surface inclination. We also found a negative correlation between sponge abundance and the abundance of erect algae, CCA (note that this was only based on the result of the RDA) and especially algal canopy cover. A considerable number of sponge species $(>80 \%)$ were strongly positively associated with the degree of surface inclination and turbidity and negatively correlated with the percentage of canopy, CCA and erect algal cover. In contrast, only a few sponge species were positively correlated with algae. This is in contrast to what was reported for the Mediterranean by Preciado \& Maldonado (2005), where a higher proportion of species were strongly correlated with algal abundance.

Despite the overall negative correlation between sponge and algal abundance that we observed, some individual species showed the reverse pattern. It is possible that some sponge species, such as Polymastia spp. and Haliclona sp. 2, might be adapted to high light habitats that are generally dominated by fastgrowing algae. Turon et al. (1998) found that growth rates were higher for sponges inhabiting high-light habitats compared to shaded habitats in the western Mediterranean. These authors argued that these sponge species have an opportunistic strategy in such habitats, which are dominated by fast-growing algae that might outcompete the sponges when space is limited, as the sponges are able to colonise the patches of bare substratum that frequently become available when algae die (because algae tend to be short lived).

The low explanatory value obtained when overall sponge cover was correlated with algal and CCA cover is most likely a result of the high variability recorded in the sponge cover, as we considered sponges as a single group, rather than constituent species. This problem could explain why other au- 
thors have not found a negative relationship between both groups, as it is difficult to show a clear pattern if different sponges show different responses to algal abundance and other environmental factors. Supporting this, our analysis at species level showed variable responses by different sponge species to algal abundance; however, negative correlations were much more common. Previous studies have reported contrasting patterns with respect to the effect of algal canopies on sponge species. For example, Kennelly (1987, 1989) did not find any relationship between shade or scour produced by Ecklonia radiata on the growth and abundance of the sponge Myxilla sp. in Australia. However, Eckman \& Duggins (1991) found that higher sedimentation rates existed beneath kelp canopies in Washington (USA), but this did not result in higher mortality of Myxilla sp.; however, these authors also found that sediment deposition negatively affected the sponge's growth (noting that their study organisms had been collected from a sediment-free environment). Thus, the probability of finding a negative effect of light and sedimentation were highly likely because it has been demonstrated that both factors may be detrimental for some species (Jokiel 1980, Maldonado et al. 2008). In contrast, some sponge species appear to be positively influenced by conditions (e.g. shade and sedimentation) that occur underneath the canopy (Smith 1996, Bulleri et al. 2002).

The effect of surface inclination on sessile organisms has been considered extensively (Barnes 1995, Turon et al. 1998, Baynes 1999, Bell \& Barnes 2000b,c, Maughan \& Barnes 2000, Bell 2001, Irving \& Connell 2002, Knott et al. 2006, Walker et al. 2007). Generally, sessile invertebrates are more abundant on vertical and overhanging surfaces compared to inclined and horizontal surfaces (Witman \& Sebens 1990, Baynes 1999, Irving \& Connell 2002, Konar \& Iken 2005). Different surface inclinations have been previously correlated with differences in the composition and diversity of sponge assemblages (Bell \& Barnes 2000b,c, Bell \& Smith 2004) as well as the growth of some species (Knott et al. 2006). Our results support these previous studies and highlight the importance of small-scale environmental variability in influencing sponge assemblage structure. These differences between surface inclinations may be explained by the different levels of disturbance (e.g. from sedimentation) occurring on horizontal compared to vertical or overhanging surfaces, which may affect sponge species and especially competition between sponges and algae (Bell \& Barnes 2000b). Algal whiplash effects will also differ among surface inclinations (see Konar \& Estes 2003) as algal abundance is reduced, which could affect the settlement of sponges. Despite the potential for algalsponge interactions to cause the patterns we reported, Maldonado \& Young (1996) suggested that the dominance of sponges on vertical and overhanging surfaces at bathyal depths, where light and macroalgae do not occur, demonstrate that factors other than competition with macroalgae are responsible for these patterns. However, we believe that in shallow water, competition with macroalgae cannot be discarded as an important factor influencing the distribution of sponges.

Depth has been considered an important factor influencing sponge distribution patterns (Wilkinson \& Evans 1989, Diaz et al. 1990, Witman \& Sebens 1990) through its relationship with physical factors, particularly light, the degree of disturbance from wave action and sedimentation (Wilkinson \& Evans 1989), and its impact on algae as a sponge competitor. Our results showed a significant interaction between site and depth, with depth being important to explain differences in community structure at 3 sites. However, the effect of depth was less important than other physical variables measured at our study sites (e.g. sedimentation).

In conclusion, sponge abundance was negatively correlated with algal abundance, which is consistent with a number of previous studies carried out in northern latitudes, but contradicts findings from an earlier study in the southern hemisphere. Nevertheless, we acknowledge that we have only demonstrated a correlation between these groups, and further manipulative experimental approaches are needed to critically identify the factors and mechanisms explaining the interactions occurring between sponges and the algal canopy. The distribution and abundance of sponges cannot be attributed to substratum inclination alone because this factor also affects algae. In fact, several physical factors, including inclination and settled sediment, as well as biological factors (including the abundance of canopy forming species, erect algae and CCA) correlate with the spatial distribution and abundance of sponge assemblages at our study sites.

Acknowledgements. The authors thank all of the divers and skippers at the Victoria University Coastal Ecology Lab (VUCEL) for help and support during diving activities. We also thank J. Berman for confirming certain sponge identifications and S. Geange, E. Newcombe and T. Jones for their helpful advice. C.A.C. was funded by a CONICYT-VUW PhD Scholarship. 


\section{LITERATURE CITED}

Advanced Graphics Software (1999) SlideWrite Plus user's guide. Advanced Graphics Software, Encinitas, CA

Anderson MJ (2001) A new method for non-parametric multivariate analysis of variance. Austral Ecol 26:32-46

Anderson MJ, Gorley RN, Clarke KR (2007) Permanova for PRIMER: guide to software and statistical methods. PRIMER-E, Plymouth

> Ayling AM (1981) The role of biological disturbance in temperate subtidal encrusting communities. Ecology 62: 830-847

> Ayling AM (1983) Factors affecting the spatial distributions of thinly encrusting sponges from temperate waters. Oecologia 60:412-418

Barnes DKA (1995) Sublittoral epifaunal communities at Signy Island, Antarctica. II. Below the ice foot zone. Mar Biol 121:565-572

Barthel D, Gutt J, Tendal OS (1991) New information on the biology of Antarctic deep-water sponges derived from underwater photography. Mar Ecol Prog Ser 69:303-307

Battershill CN, Murdoch RC, Grange KR, Singleton RJ, Arron ES, Page MJ, Oliver MD (1993) A survey of the marine habitats and communities of Kapiti Island. Department of Conservation, Wellington

Baxter A (1987) Kapiti Island: subtidal ecology survey. In: Book 87/2. MAF Central Fisheries Area Internal Report, Napier, New Zealand

Baynes TW (1999) Factors structuring a subtidal encrusting community in the southern Gulf of California. Bull Mar Sci 64:419-450

> Bell JJ (2001) The influence of water flow rate, depth and surface inclination on the density and the distribution of five species of temperate anthozoa at Lough Hyne, Ireland. J Mar Biol Assoc UK 81:883-884

> Bell JJ (2002) The sponge community in a semi-submerged temperate sea cave: density, diversity and richness. PSZN I Mar Ecol 23:297-311

Bell JJ (2007) The ecology of sponges in Lough Hyne Marine Nature Reserve (south-west Ireland): past, present and future perspectives. J Mar Biol Assoc UK 87:1655-1668

Bell JJ, Barnes DKA (2000a) A sponge diversity centre within a marine 'island'. Hydrobiologia 440:55-64

Bell JJ, Barnes DKA (2000b) The distribution and prevalence of sponges in relation to environmental gradients within a temperate sea lough: inclined cliff surfaces. Divers Distrib 6:305-323

Bell JJ, Barnes DKA (2000c) The distribution and prevalence of sponges in relation to environmental gradients within a temperate sea lough: vertical cliff surfaces. Divers Distrib 6:282-303

Bell JJ, Barnes DKA (2000d) The influences of bathymetry and flow regime upon the morphology of sublittoral sponge communities. J Mar Biol Assoc UK 80:707-718

Bell JJ, Barnes DKA (2003) Effect of disturbance on assemblages: an example using porifera. Biol Bull 205:144-159

Bell JJ, Smith D (2004) Ecology of sponge assemblages (Porifera) in the Wakatobi region, south-east Sulawesi, Indonesia: richness and abundance. J Mar Biol Assoc UK 84:581-591

> Berman J, Bell JJ (2010) Spatial variability of sponge assemblages on the Wellington South Coast, New Zealand. The Open Mar Biol J 4:12-25

Bray JR, Curtis JT (1957) An ordination of the upland forest communities of southern Wisconsin. Ecol Monogr 27:
325-349

> Bulleri F, Benedetti-Cecchi L, Acunto S, Cinelli F, Hawkins SJ (2002) The influence of canopy algae on vertical patterns of distribution of low-shore assemblages on rocky coasts in the northwest Mediterranean. J Exp Mar Biol Ecol 267:89-106

Carballo JL (2006) Effect of natural sedimentation on the structure of tropical rocky sponge assemblages. Ecoscience 13:119-130

Carter L, Lewis K (1995) Variability of the modern sand cover on a tide and storm driven inner shelf, south Wellington, New Zealand. NZ J Geol Geophys 38:451-470

Chiswell SM, Stevens CL (2010) Lagrangian and Eulerian estimates of circulation in the lee of Kapiti Island, New Zealand. Cont Shelf Res 30:515-532

Clarke KR, Gorley RN (2006) PRIMER v6: user manual/ tutorial, Vol 1. PRIMER-E, Plymouth

> Dayton PK, Robilliard GA, Paine RT, Dayton LB (1974) Biological accommodation in the benthic community at McMurdo Sound, Antarctica. Ecol Monogr 44:105-128

de Voogd NJ, Becking LE, Cleary DFR (2009) Sponge community composition in the Derawan Islands, NE Kalimantan, Indonesia. Mar Ecol Prog Ser 396:169-180

Diaz MC, Rützler K (2001) Sponges: an essential component of Caribbean coral reefs. Bull Mar Sci 69:535-546

Diaz MC, Alvarez B, Laughlin RA (1990) The sponge fauna on a fringing coral reef in Venezuela, II: community structure. In: Rützler K (ed) New perspectives in sponge biology. Smithsonian Institution Press, London, p 367-375

Eckman JE, Duggins DO (1991) Life and death beneath macrophyte canopies: effects of understory kelps on growth rates and survival of marine, benthic suspension feeders. Oecologia 87:473-487

Ginn BK, Logan A, Thomas MLH (2000) Sponge ecology on sublittoral hard substrates in a high current velocity area. Estuar Coast Shelf Sci 50:403-414

Irving AD, Connell SD (2002) Sedimentation and light penetration interact to maintain heterogeneity of subtidal habitats: algal versus invertebrate dominated assemblages. Mar Ecol Prog Ser 245:83-91

Jokiel PL (1980) Solar ultraviolet radiation and coral reef epifauna. Science 207:1069-1071

> Kennelly SJ (1987) Physical disturbances in an Australian kelp community. II. Effects on understorey species due to differences in kelp cover. Mar Ecol Prog Ser 40:155-165

Kennelly SJ (1989) Effects of kelp canopies on understorey species due to shade and scour. Mar Ecol Prog Ser 50: 215-224

Knott NA, Underwood AJ, Chapman MG, Glasby TM (2004) Epibiota on vertical and on horizontal surfaces on natural reefs and on artificial structures. J Mar Biol Assoc UK 84: 1117-1130

Knott NA, Underwood AJ, Chapman MG, Glasby TM (2006) Growth of the encrusting sponge Tedania anhelans (Lieberkuhn) on vertical and on horizontal surfaces of temperate subtidal reefs. Mar Freshw Res 57:95-104

Kohler KE, Gill SM (2006) Coral Point Count with Excel extensions (CPCe): a Visual Basic program for the determination of coral and substrate coverage using random point count methodology. Comput Geosci 32:1259-1269

Konar B, Estes JA (2003) The stability of boundary regions between kelp beds and deforested areas. Ecology 84: 174-185

Konar B, Iken K (2005) Competitive dominance among sessile marine organisms in a high Arctic boulder commu- 
nity. Polar Biol 29:61-64

Leps J, Smilauer P (2003) Multivariate analysis of ecological data using CANOCO. Cambridge University Press, Cambridge

Maldonado M, Young CM (1996) Bathymetric patterns of sponge distribution on the Bahamian slope. Deep-Sea Res I 43:897-915

Maldonado M, Giraud K, Carmona C (2008) Effects of sediment on the survival of asexually produced sponge recruits. Mar Biol 154:631-641

Maughan BC, Barnes DKA (2000) Epilithic boulder communities of Lough Hyne, Ireland: the influences of water movement and sediment. J Mar Biol Assoc UK 80: 767-776

Preciado I, Maldonado M (2005) Reassessing the spatial relationship between sponges and macroalgae in sublittoral rocky bottoms: a descriptive approach. Helgol Mar Res 59:141-150

Roberts DE, Davis AR, Cummings SP (2006) Experimental manipulation of shade, silt, nutrients and salinity on the temperate reef sponge Cymbastela concentrica. Mar Ecol Prog Ser 307:143-154

Sarà M, Balduzzi A, Barbieri M, Bavestrello G, Burlando B (1992) Biogeographic traits and checklist of Antarctic demosponges. Polar Biol 12:559-585

Shears N, Babcock R (2007) Quantitative description of mainland New Zealand's shallow subtidal rocky reef communities. Science for Conservation 280, NZ Department of Conservation, Wellington

Smith SDA (1996) The macrofaunal community of Ecklonia radiata holdfasts: variation associated with sediment regime, sponge cover and depth. J Ecol 21:144-153

Editorial responsibility: Sean Connell, Adelaide, Australia
Teixidó N (2003) Analysing benthic communities in the Weddell Sea (Antarctica): a landscape approach. PhD Thesis, University of Bremen

ter Braak CJF, Smilauer P (2002) CANOCO Reference manual and CanoDraw for Windows user's guide: software for canonical community ordination (version 4.5). Microcomputer Power, Ithaca, NY

Turon X, Tarjuelo I, Uriz MJ (1998) Growth dynamics and mortality of the encrusting sponge Crambe crambe (Poecilosclerida) in contrasting habitats: correlation with population structure and investment in defence. Funct Ecol 12:631-639

> Walker SJ, Schlacher TA, Schlacher-Hoenlinger MA (2007) Spatial heterogeneity of epibenthos on artificial reefs: fouling communities in the early stages of colonization on an East Australian shipwreck. PSZN I Mar Ecol 28: 435-445

> Wilkinson CR, Evans E (1989) Sponge distribution across Davies Reel Great Barrier Reef relative to location, depth, and water movement. Coral Reefs 8:1-7

Wilkinson CR, Vacelet J (1979) Transplantation of marine sponges to different conditions of light and current. J Exp Mar Biol Ecol 37:91-104

Witman JD, Sebens KP (1990) Distribution and ecology of sponges at a subtidal rock ledge in the Central Gulf of Maine. In: Rützler K (ed) New perspectives in sponge biology. Smithsonian Institution Press, London, p 391-396

Zea S (1994) Patterns of coral and sponge abundance in stressed coral reefs at Santa Marta, Colombian Caribbean. In: van Soest RWM, van Kempen TG, Braekman JC (eds) Sponge in time and space: biology, chemistry, paleontology. AA Balkema, Rotterdam, p 257-264

Submitted: January 20, 2012; Accepted: May 28, 2012 Proofs received from author(s): July 28, 2012 